\title{
Analyzing Affordances of Digital Occupational Health Systems
}

\author{
Maedeh Yassaee \\ University of St. Gallen \\ maedeh.yassaee@unisg.ch
}

\author{
Robert Winter \\ University of St. Gallen \\ robert.winter@unisg.ch
}

\begin{abstract}
This study adopts two distinct perspectives, employer and employee, to analyze the affordances of digital occupational health $(\mathrm{DOH})$ systems and their appropriation. Data were collected in the context of a European collaborative research project that aims at developing a data integration infrastructure for context-aware health surveillance at the workplace. For employers the main affordance was to detect and prevent the health issues of their workforce. The main affordance from employee's point of view was the possibility of being more self-conscious at work. However, the application of these systems might instigate several tensions, in particular those between privacy and security/wellbeing, between work and leisure activities, and between work and leisure roles. The findings of this study allow to direct future research on DOH systems to focus and eventually derive design principles that promise DOH systems to gain better acceptance and create higher added-value for all involved stakeholders.
\end{abstract}

\section{Introduction}

A high rate of work-related accidents and diseases, as well as the rapid aging of the world's population, have not only had an impact on corporate productivity and profitability, they also threaten the lives of employees [1]. Following advancements in low-cost and unobtrusive wearable computing devices, employers have begun providing their employees with wearable devices as part of their occupational safety and health prevention strategy (e.g., $[2,3])$. Wearable computing devices, in concert with algorithmic decision-making, quantified feedback with the ability to handle contextual awareness, subject-specific models, and personalization, can facilitate employees' active management and improvement of their health and wellbeing at work [4-6]. In this study, the term digital occupational health $(\mathrm{DOH})$ is used to refer to these types of technologies. Analyzing the aggregated environmental, physiological, and psychological data of the workforce may bring forth unknown and as yet hidden workplace dynamics. Actionable insights from the analysis of these dynamics will help employers improve the work environment such that employees will become healthier and more productive [7].

Although the adoption of digital health monitoring systems has been studied in both private and clinical contexts, the corporate adoption of these systems would have distinct characteristics. Sensitive and highly personal health-related information collected in a non-health context impacts employees' security and privacy in ways that make sharing, aggregating, sorting, and analyzing the data particularly challenging [8]. Furthermore, DOH systems involve different types of stakeholders as end users (both employees and employers), with possible conflicts among their use intentions. In cases of conflict, employees can either completely reject the adoption of technology, or selectively adopt particular features [9].

While the scientific community has begun to show interest in the design, implementation, and deployment of DOH systems (e.g., [10, 11]), the focus has primarily been on technical aspects. Consequently, the literature is currently missing any substantial reference to how organizations should be prepared for DOH adoption and its consequences in terms of impact, change, and readiness of the organization's social structure. To enhance the general understanding of the dynamic interactions among the social actors and the DOH artifact, as well as DOH's influences on employees' attitudes and impacts on their behavior, we rely upon a framework rooted in technology affordances theory employed in management information systems (MIS) [12]. Thus, our research addresses the following research questions:

- What do users expect from the introduction of DOH systems to their companies?

- How will the introduction of DOH systems influence users' beliefs and actions?

This research is structured as follows: Section 2 reviews prior studies on personal health monitoring systems and the affordance concept. Section 3 details our research setting, data collection, and analysis procedures. Section 4 summarizes our findings. In section 5 , based on the evidence we obtained from two quali- 
tative inductive case studies, we analyze both the practical and theoretical implications of the adoption of DOH systems. This discussion is followed by the conclusion and outline of future work.

\section{Background}

\subsection{Personal health monitoring systems}

Personal health monitoring systems (PHMS) include "any electronic device or system that monitors and records data about a health-related aspect of a person's life" [13]. PHMS emphasize the provision of self-care services to individuals. Such services involve any stage of the care cycle, and enable the prevention, early diagnosis, and management of chronic diseases [14]. These systems have also been used for a wide range of other purposes, including the physiological monitoring of healthy people, safety monitoring, home rehabilitation, the assessment of treatment efficacy, and early detection of disorders [15]. Thus, their main purpose is to provide a means of self-engaging with and managing individuals' health statuses and minimizing their interactions with healthcare actors. However, legal and societal obstacles, issues related to the real application of wearable devices, inappropriate use of support systems, and the skepticism of many healthcare professionals have resulted in few effective implementations [14].

The technologies required to enable PHMS goals consist of three main categories: sensing and data collection hardware for collecting physiological, movement, and environmental data; communication hardware and software for relaying data to a remote center; and data analysis techniques for extracting clinically relevant information from the physiological and movement data. PHMS technologies are personalized (tailored to each user's needs), adaptive (responsive to the user and their environment), and preventative (they anticipate users' desires as far in the future as possible, without conscious mediation). The miniaturization of sensors and electronic circuits based on the use of microelectronics has played a key role in the development of PHMS. Measuring physiological aspects such as heart rate, respiratory rate, blood pressure, blood oxygen saturation, and muscle activity are some of these sensors' capabilities [15]. Wearable devices must be unobtrusive, easy to use, comfortable to wear, efficient in power consumption, privacy compliant, and offer a very low failure rate and high level of accuracy for triggering alarms, especially if used for diagnostic purposes [16]. Wearable sensors are often combined with ambient sensors when subjects are monitored in a closed environment $[15,17]$.

\subsection{Affordance concept}

The concept of affordance in information systems (IS) research [9, 18-21] has its roots in ecological psychology [22]. The focus of this theory is on the possibility of actions that an object in an environment offers to an organism, either for good or ill [22]. In Gibson's view, an affordance cuts across the subjective-objective dichotomy and helps us understand its inadequacy [22]. A simple example of an affordance is the sit-ability of a tree stump. The actualization of this affordance depends upon human needs, the sitting individual's characteristics, use context, and properties of the tree stump. For instance, the stump's size and height should match the body size of the person sitting on it. But the sit-ability of the tree stump is also affected by the seating opportunities in its direct neighborhood.

Majchrzak and Markus [12] define technology affordance as "action potential, that is, to what an individual or organization with a particular purpose can do with a technology or information system." Their technology affordance concept emphasizes how social and material agents interact in an organizational setting, how people use information systems, and how the use of information systems affect individuals, organizations, and their performance. The concept of technology affordance facilitates theories on the effects of introducing new systems into organizations [23]. Affordances can bridge the gap between theories that emphasize only psychological or social behaviors and concepts that ignore the role of human intention and behavior [24, 25].

Leonardi [9] explains how the introduction of information technology into an organization, as viewed through the affordance lens, either adjusts the routines of social actors or produces new affordances for the technology, that were not initially intended by the system's designers. The application of an affordance perspective to the introduction of $\mathrm{DOH}$ systems to organizations allows us to gain a clearer understanding of the interplay among social actors (as people or organizational intents) and technical artifacts.

The affordances exist in relation to artifacts characterized by their features, and social actors with specific areas of expertise and goals [26]. Affordances are conditions that enable interactions among users and DOH artifact [27]. These conditions include properties related to the social actor (e.g., individual and organizational intentions, expectations, motivations, needs, and knowledge) and the technical artifact (its functions or features) [8].

Building upon this theory of affordance, the model in Figure 1 displays the process of affordance appropriation as the user chooses how to utilize an ar- 
tifact's features and produces certain effects [28]. Affordances are preconditions for an action. As the potential for action, they must be actualized by the social actor to realize their potential or effect [23]. The actualization of affordances may be influenced by any factors related to the social and technical properties of the interaction.

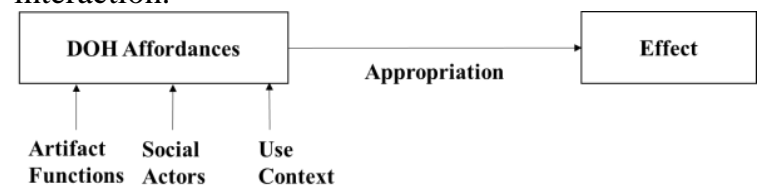

Figure 1. Affordance appropriation framework

\section{Method}

\subsection{Research setting}

The results presented in this study are based on two instrumental cases, the two pilot studies of the Active@work project [29]. This project was funded by the European Commission and the Swiss State Secretariat for Education, Research, and Innovation. This work supports senior employees in their effort to efficiently perform job-related tasks without risking their health. The goal of Active@work is proper management of the negative impacts of aging and work-related health issues such as stress and fatigue - both physiological and psychological - on employees' performance and productivity. The project's team is currently developing an innovative data integration infrastructure for context-aware surveillance, meaning that data are analyzed according to two main dimensions: the health status of each individual and the environmental conditions of the workplace. Figure 2 illustrates an overview of this system. In order to accomplish the project's goal, the solution will:

- Monitor the health statuses of senior employees in the workplace through wearable devices capable of periodically collecting data (e.g., ECG, glycaemia, blood pressure, pulse rate, body temperature, etc.);

- Monitor the environmental conditions in the workplace with the help of environmental

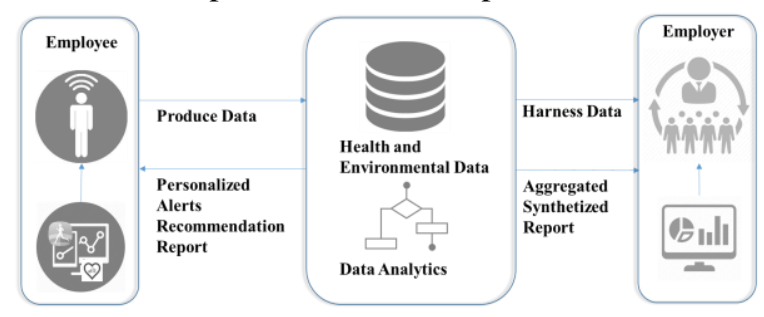

Figure 2. Active@work system overview sensors (e.g., air quality, temperature, noise, etc.);

- Wirelessly report these data to a central server for processing;

- Provide operational intelligence with a proactive model and predictive algorithms for recognizing behavioral trends and early detection of personal health risks;

- Provide personalized reports to employees;

- Provide aggregated reports to employers; and

- Trigger alert messages when the thresholds related to individual health conditions are exceeded.

Deployment of the system will be conducted in two dissimilar work environments in the services sector. One pilot study is located in an international IT services company that offers end-to-end consulting, systems integration, and managed services. This pilot (the white collar pilot) includes the participation of senior consultants and/or directors facing a high level of mental pressure, low level of physical activity, and long work hours. The other pilot study (the blue collar pilot) is in a leisure park designed as a location for people to spend their holidays while enjoying diverse recreational options. Facilities are both indoors and outdoors, appropriate for all ages, include relaxing or exciting activities, and offer opportunities to shop, eat, and drink. This pilot addresses the park's technical maintenance staff and operational management team. These maintenance employees experience a high physical workload because of the size of the leisure park and short timespan within which defects must be corrected.

\subsection{Data collection}

We have adopted an inductive qualitative design for use in our research study [30]. Two rounds of semistructured interviews were conducted at the pilot sites. To recruit interviewees, we followed a purposive sampling strategy and actively involved employees likely to be affected by the introduction of a DOH system by their employer. Twelve interviews with nine white collar and three blue collar workers were conducted between June and September of 2015. The respondents taking part in the qualitative inquiry (five men and seven women) were, on average, 48 years of age of age and had worked for approximately 12 years in their current positions. Three of the respondents were working in management positions and nine had no management responsibilities. Each interview lasted approximately 60 minutes and began with broad, unobtrusive questions regarding the pilot company's current occupational health program and participants' previous personal experiences with quantified self-technologies 
(at work and/or in the home). This was followed by a clear definition of what we understood to be a DOH system, and more specific questions regarding the possible role of DOH technology in the interviewees' work environments. During the interviews, we permitted an ongoing process of refocusing and reconceptualization, as suggested by Bouchard [31], in order to allow the interviewees to reformulate their ideas more precisely, using examples from their daily work experiences.

All interviews were recorded and the answers were transcribed verbatim; subsequently, these transcriptions were returned to the interviewees so that they could perform timely reviews for accuracy. In order to systematically analyze the interview transcripts, we used open coding [32]. The coding process began with two researchers classifying all of the open codes, in order to derive meaningful concepts. Differences of opinion among the researchers were discussed until they agreed upon a set of concepts.

\section{Findings}

The outcome of the data analysis was two sets of expected affordances for employees and employers, as well as three influencing factors related to affordance appropriation (values, roles, and action tensions). Below, we explain the distinct categories that emerged from the inductive data analysis. Our findings are supported by citations from the case data.

\subsection{DOH affordances}

In this study, we identified two sets of affordances for the "employer" and "employee" user groups. Table 1 provides a synthesis of our findings.

We observed two different types of affordances from the employer's point of view. The first was the possibility of finding patterns in employee work behaviors and detecting and preventing the root causes of particular health issues. Within this affordance, employers would be directly involved in harnessing aggregated data and actively intervening in the work environment if the system's findings warranted it. One manager from the white collar pilot believed that finding such patterns would be the main functionality of the system; she could not imagine a need for monitoring employees and their environments for long period of time to determine work patterns. "We do not need to monitor employees and their environment for one year. Maybe with one month, we can detect things in [the] working environment to change or working process that might improve. In big companies like ours ... we cannot be with everyone ... detecting patterns that can improve the [ir] quality of life." Another management-level interviewee could not imagine finding patterns for some sort of jobs: "Finding the patterns would be interesting but it depends on the job, like in $R E$ all the tasks are very different; for knowledge worker[s] it is not easy to detect patterns. I could imagine in programing and coding, there are some patterns."

The other affordance for employer was the possibility of mitigating health-related risks and injuries. The actualization of this affordance would depend upon employees' effective use of the system. Even though the employer could not be directly involved in actualization of this affordance, they could indirectly be involved with defining strategies to motivate employees to adopt and use the system. "I think the performance of individual[s] and [the] organization is interrelated. Since we cannot force them to use the system, we should motivate them with [a] small bonus or whatever. It can be small or stupid but it can change a lot. Something weird or fun like having breakfast with the boss. It should not be something important but motivating ... giving the feeling of belonging to a group and making people happier."

We categorized the employee affordances into functional ones, physical ones, and those related to information quality and security. Functional affordances help employees accomplish the goal of health enhancement. The main functional affordance from the employee's point of view was the possibility of being more self-conscious. "We are not conscious of our health [and] in particular our stress. Maybe it [would be] interesting to have [a] different point of view, even it is from a machine. The other employee affordance was the possibility of preventing health issues. "Stress is something important in our job and [a] precondition for our health. I had some people with [a] high level of stress for [a] long time and I saw how their health [was] impacted by that.

Another important affordance for interviewees was long-term support in managing their health and changing bad habits. "It can be an assistance to improve and manage my health. I am now 40 but when I am 55, I do not know if I can handle this level of stress. Right now [a] high [heart] rate is acceptable but when I am 55, it is not. If I cannot manage it right now, it will be a big problem when I become older. I think preventing and changing my [bad] habit[s] in this stage will help me when I am old. I [would] also like to know the things that maybe I do not know now."

Interestingly, some interviewees expected some economic benefit from using the system. "You can sell the data to who is interested in it. Now companies like Nike or others use the data generated by people [for] free [and] it should not be free." 
Physical affordances are related to the properties of the system's wearable device. Most of the interviewees expected an ergonomic wearable device that would not afford any harm or distractions. "If it is easy to wear, I do not have [a] problem. If it is useful, I can force myself to wear it as long as it is ergonomic." Some of the interviewees expected that the system would offer them a secure wearable device that would not easily break. "I do not have any problem [with] wear[ing] it if it is not ... disturbing. I am used to it because I had to wear something to monitor my heart rate because of my heart problem. However, my problem is not that. I am more concern[ed] about if I break it or I forget it somewhere."

Table 1. DOH affordances

\begin{tabular}{|c|c|c|}
\hline & \multirow{3}{*}{ 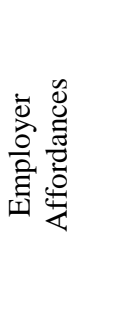 } & $\begin{array}{l}\text { To afford the possibility of detecting } \\
\text { and preventing the root causes of } \\
\text { health issues }\end{array}$ \\
\hline & & $\begin{array}{l}\text { To afford the possibility of finding } \\
\text { patterns in employees' work behaviors }\end{array}$ \\
\hline & & $\begin{array}{l}\text { To afford the possibility of mitigating } \\
\text { health-related risks and injuries }\end{array}$ \\
\hline \multirow{11}{*}{ 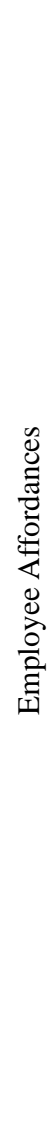 } & \multirow{5}{*}{ 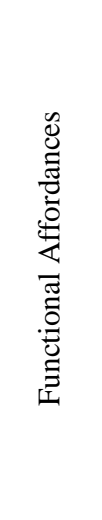 } & $\begin{array}{l}\text { To afford the possibility of increasing } \\
\text { self-consciousness }\end{array}$ \\
\hline & & $\begin{array}{l}\text { To afford the possibility of detecting } \\
\text { and preventing health issues }\end{array}$ \\
\hline & & $\begin{array}{l}\text { To afford the possibility of changing } \\
\text { behaviors at work }\end{array}$ \\
\hline & & $\begin{array}{l}\text { To afford the possibility of receiving } \\
\text { economic benefits }\end{array}$ \\
\hline & & $\begin{array}{l}\text { To afford the possibility of long-term } \\
\text { health management and preventing se- } \\
\text { rious health-related issues later in life }\end{array}$ \\
\hline & \multirow{3}{*}{ 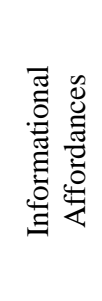 } & $\begin{array}{l}\text { To afford the possibility of privacy } \\
\text { protection }\end{array}$ \\
\hline & & $\begin{array}{l}\text { To afford the possibility of secure data } \\
\text { protection }\end{array}$ \\
\hline & & $\begin{array}{l}\text { To afford the possibility of receiving } \\
\text { accurate information }\end{array}$ \\
\hline & \multirow{3}{*}{ 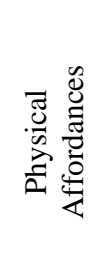 } & $\begin{array}{l}\text { To afford the possibility of protecting } \\
\text { the physical security of the device }\end{array}$ \\
\hline & & $\begin{array}{l}\text { To not afford the possibility of physi- } \\
\text { cal harm (wearable) }\end{array}$ \\
\hline & & $\begin{array}{l}\text { To not afford the possibility of disturb- } \\
\text { ing and distracting }\end{array}$ \\
\hline
\end{tabular}

Finally, information affordances offer secure and accurate interactions with the system. Regarding privacy, one interviewee mentioned, "I am not an important person but it is ethical to keep my information protected. For example, on my mobile I'd not activate my location unless I [was] travelling and I need[ed] my family to know where I am, otherwise my location is not available ... I take the active position to protect my personal data and I expected the system will do the same." Data accuracy was another affordance employees expected from the system: "If I receive an alert, it should be accurate." In addition, most of the interviewees expected that the system would offer a secure environment for their personal data: "This is the key of the system. It is dependent [on] the information. Medical information is more sensitive. My movement ... is not important. Having the insurance to have the security is so important for me. I need to have the power to manage my data."

\subsection{Affordance appropriation}

The following subsection presents factors that influence the appropriation of affordances by employees.

\subsubsection{Role tension}

A role, as a given social position, is a process that includes three components: (1) structurally-given demands such as norms, expectations, and responsibilities; (2) personal role conception as the inner definition of what someone should think and do; and (3) role behavior as the ways in which members of a particular position act (with and without conscious intention) [33]. It has been argued an individual's choices are shaped by how that person organizes their total role system and performs well or ill in any role relationship [34]. Role tension can occur as the result of incompatibilities among the many demands of an employee's work environment, such as contradictory expectations, incompatibilities among certain organizational practices, or inadequate resources to perform tasks [35]. Research evidence has indicated that dysfunctional individuals and organizational consequences result from the existence of role tension [36].

The adoption of a DOH device could result in two different types of role tension: inter-role tension, in which an end user has to find a balance in his/her role system while interacting with the conflicting demands of the DOH system, and intra-role tension, which happens when two stakeholders have conflicting expectations regarding the affordances of the system.

With inter-role tension, some interviewees brought up conflicts between their leisure and work 
roles that resulted in stress. "You know, when I have a deadline and I am so stressed I need to only focus on my work and finish it as soon as possible; then I can go home and relax and be with my family. I try to separate my personal and working lives. I prefer to focus on my work when I am in the office. But if I receive alerts and recommendation[s] to take a break or something it [will] just disturb me and make me nervous." Another example of inter-role tension occurs when interacting with the system results in conflicts between different work-related roles held by the same person. A management-level interviewee valued the possibility of using DOH to control employees, but at the same time, she was herself an employee concern about her privacy. "As an employee, I see the benefit; as a manager, I see the benefit...However, this data is so sensitive. It is so important. I am keeping everything secure and protect $[\mathrm{ed}]$."

With intra-role tension, we observed that potential management-level users had different views regarding the various $\mathrm{DOH}$ affordances than did employees without any management responsibilities. For instance, while managers tended to be positive about the affordance of employee motivation, believing that gamification and competition might inspire employees to change bad behaviors, employees without management responsibilities were more interested in improving their own levels of self-consciousness through the visibility affordance. They were not at all interested in competing with their colleagues. Mostly, the management-level interviewees made statements such as, "From my point of view, motivation is so important. It is important to motivate people. If the employees could share their performance with colleagues or when [they] want to quit a habit like smoking they can compete and [at] the end of the month the winner could get a trophy or a bonus. " On the other hand, employees without management responsibilities mostly responded with: "I am not interested in any competition; it should be as simple as possible; then it can help."

\subsubsection{Value tension}

Value tension has been defined in the literature as situations in which two values that are both important come into conflict. While in some situations there is no other option than to choose one value over the other, it is often helpful to think of ways in which both values can be honored [37]. Newell and Marabelli discuss value tensions related to digital monitoring systems, such as privacy versus security, freedom versus control, and dependence versus independence [38]. Below, each of these value tensions are explained in the context of DOH adoption, as well as how the interviewees' perceptions of these tensions might influence their interaction with the system.

Privacy versus Security and Wellbeing: While the personalization of data offers health and wellbeing enhancement and a greater level of security at work, the possibility that personal data might be used by the employer or a third party for discriminatory purposes threatens employees' privacy. Most of the interviewees perceived this value tension as a constraint on the system adoption. "I see the benefit of the system, but how about my privacy?" One interviewee brought up some risks related to the possibility of employers getting access to employees' health-related information. "I am sure if some managers have access to medical information of the[ir] employees, they could use it for good and bad, like reducing ... work pressure ... it can be bad to fire someone who is sick or is pregnant." However, if they were sure that the system would secure and protect their data according to the law, they might consider using the system and letting the organization analyze their anonymized aggregated data. "[Personal] data is so sensitive. However, I suppose that it is supported in the design of such systems. In this case, I would not have any problem ... I don't care if they analyze my information in [a] group but as a person, no. I don't like it." On the other hand, some employees facing the same value tension were willing to trade their privacy for access to tangible or intangible values. For some, economic incentives would convince them to give up their privacy: "If there is an economic incentive then you say ok. I [would] give up my privacy to get money or a bonus for it. It should be balanced, you know?",

Freedom versus Control: The adoption of a DOH system means the constant tracking of every movement of the workforce, and using the data to monitor and control their behavior. Since organizations can only analyze data that have been anonymized, the potential users interviewed for this research did not perceive this as a constraint. However, Newell and Marabelli argue that if organizations classified employees into groups according to various criteria, this would result in "social sorting." It might also lead to longterm discrimination.

Independence versus Dependence: The tradeoff between independence and dependence originates from the tension between the willingness to depend on IT devices and the ability to live without them (i.e., independence). Thus far, we have discussed the potential benefits DOH can offer employers and employees. Adopting this type of system, however, could lead to employees becoming unable to engage in particular activities without it. One of the interviewees was so concerned about this dependency issue that they were 
not even willing to try it. "No, I am not going to use it. I do not like to get dependent on technology and I do not like to rely too much on technology. When I am giving a lot of power to technology, I am losing my power as a human." While other interviewees were also concerned about this issue, they could imagine finding a balance between use and dependency. "I use [a] bracelet for fitness and when I go for [a] run, I use it; and when I am done, I get rid of it. I think we need a balance [between what] we can get from technology and ... humanism."

\subsection{Action tension}

DOH's acquisition of data depends on employees' active and passive information behaviors. Employees can actively interact with DOH devices through intentional acquisition, for instance by checking their performance on their personal dashboard. In addition to the intentional seeking of health-related information, employees can also receive information without actively looking for it [39-41]. These passive interactions with DOH devices (alerts, recommendations, reminders, etc.) could demand non-work activities (e.g., taking a break, drinking water, competing with colleagues, etc.), and thus would interrupt work-related tasks. While the DOH system is expected to support employees in their effort to manage work-related stress, task interruptions caused by interactions with the technology (alerts, recommendations, reminders, etc.) could also provoke stress in work environments that include high levels of mental pressure. Studies illustrate the negative impact of work interruption on a person's psycho-physiological state [42, 43].

Employees in the white collar pilot who had jobs involving high levels of mental pressure were more concerned with the degree of disturbance generated by the system than their blue collar counterparts were. Most of the interviewees were primarily concerned with the possibility of conflict between their work and non-work activities. One interviewee mentioned, "It is also about the interaction with the device; if it asks me every 15 minutes to interact then it is invasive. " However, another respondent found this interaction beneficial. She was also concerned about mixing her public and personal lives. "Usually, at work you have [to] focus to have ... efficiency ... [The device] will add a human touch ... to [the] work environment ... There are two different type of stress which I am dealing with. If it's work-related stress, my solution is to be more efficient at work because normally stress comes from a deadline, so the only way is to work harder. Then if the system distracts me, it will make me more stressed. When it is personal, I cannot do anything about it at work."

We graphically summarize the findings of our study in Figure 3.

\section{Discussion and conclusions}

This study adopted two distinct perspectives, employer and employee, to demonstrate the affordances expected from the adoption of digitized health-promoting systems such as DOH devices. Employers were willing to adopt $\mathrm{DOH}$ technology to detect and

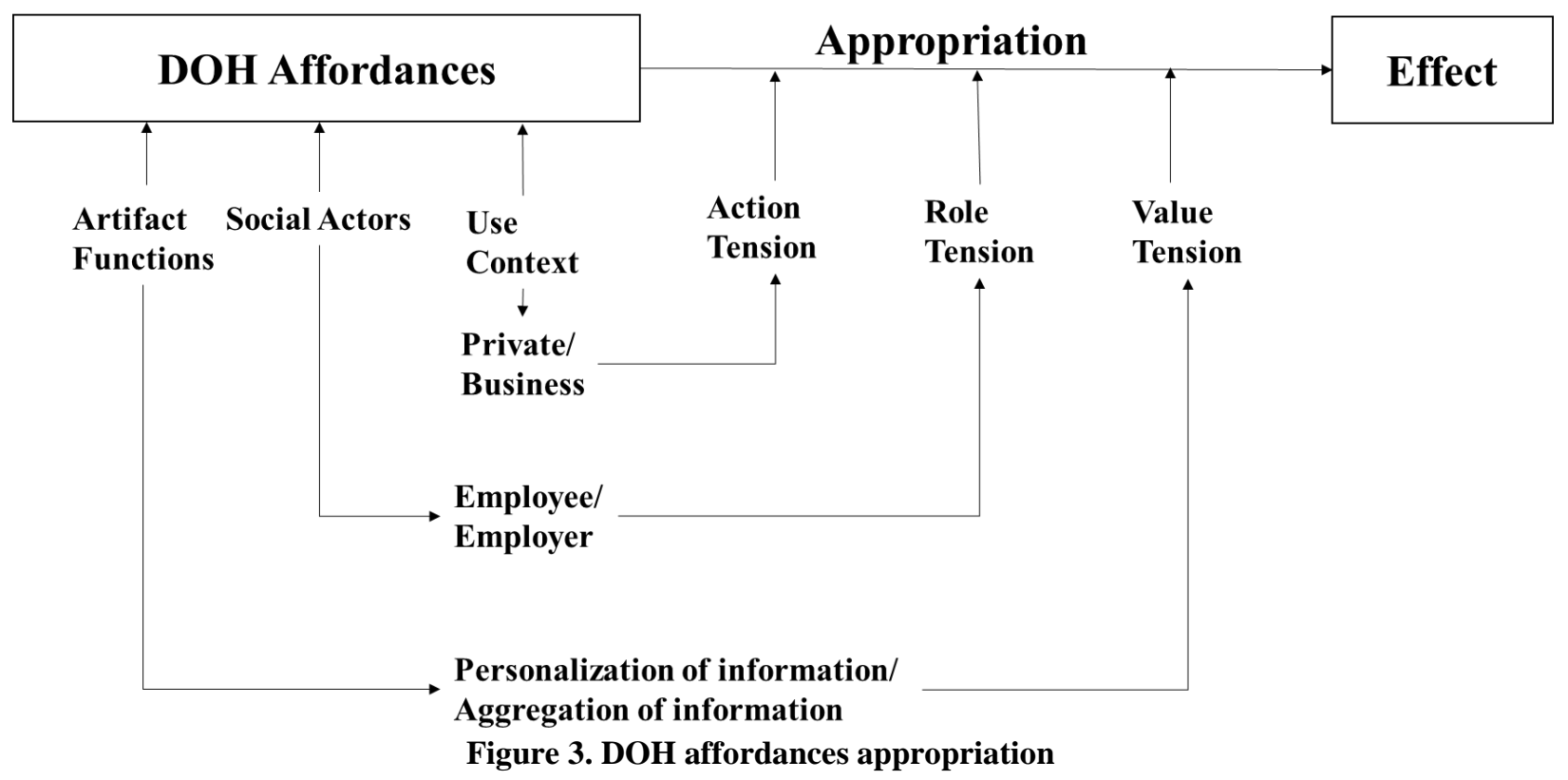


prevent the root causes of health issues and to find patterns in their employees' work behaviors that might lead them to mitigate associated health risks and injuries. In addition, for employees, the technology should also offer a means of increasing employees' level of self-consciousness at work, and additional informational and physical affordances. The expected informational affordances include privacy protection, data security, and information accuracy. The expected physical affordances relate to the physical security of the device and the absence of distraction while wearing the device at work.

We further investigated how the appropriation of these affordances might influence the beliefs and actions of employees, and found three main types of tensions that could affect the appropriation of affordances: (1) value tension (privacy vs. security and wellbeing, control vs. freedom, and dependency vs. independency), (2) action tension (work vs. leisure activities), and (3) role tension (leisure vs. work roles).

\subsection{Implications for practice and theory}

The findings of this study suggest that even though the introduction of digitized health-promoting systems offers potential benefits for both employers and employees, the application of these systems might instigate social tensions. These tensions could result in system rejection. Moreover, even if employees are successfully persuaded to use these systems, they could negatively influence employees' performance and productivity.

In this study, we focused on introducing the digitized devices in an organizational setting and presented three tensions that emerged from their adoption; we believe that they are also likely to result from the implementation of similar digital solutions introduced via the IT consumerization trend. The term IT consumerization is used to describe the increasing diffusion of technology initially designed for consumer marketplaces [44] such as social media [45], online shopping websites [46], mobile apps [47] and wearables [48] for use in an occupational context [49]. This, in turn, is influencing company structure and in the long run will affect society [50]. Consequently, we need to explore the role of IT consumerization in changing the social structure of companies and the consequences of such changes.

The findings of this research demonstrate that the integration of work and life through the adoption of this type of system may endanger stable job boundaries and increase the potential for role stress [50]. Role stress is a commonly studied work-related issue [51]. These findings also underscore the importance of action tension, which is another source of work stress.
Work stress can cause employee burnout [52] and diminished organizational commitment and performance [53]. Therefore, we suggest that future IS research should be conducted that considers the impact of these tensions on workforce productivity and performance. It would be beneficial to identify approaches to managing and preventing these negative impacts, and define the functional and managerial requirements for designing and implementing these systems.

Value tensions can cause employees to reject this type of technology. Conflicting organizational and individual expectations, and aligned expectations but conflicting approaches to appropriating values both result in value tension. For instance, though both employers and employees expect DOH technology "to afford the possibility of mitigating ... health related risks and injuries," employers could seek to appropriate this affordance by controlling employees' behaviors; this would result in value tension. On the other hand, if appropriation of this affordance by employees demands so much interaction with the system and non-related work activities in the work environment that it reduces their productivity, use of the device will conflict with the employer's goals. Thus, even if the expected affordances are aligned, the conflicting means of appropriation would cause value tension. We propose avoiding this type of tension by perceiving and analyzing the organizational value of these technologies as one would an ecosystem in which the technology's affordances and their appropriation by employers and employees are aligned and balanced.

Thus, the proper design and management of these systems requires a "big picture" view of the individual and organizational affordances and how the functions and features of the system support their appropriation. During the design phase, designers should identify different stakeholders' affordances, as well as the relevant features that would enable the appropriation of those affordances, and conflicting affordances and/or conflicting appropriations. Then, the system's architecture and features should be combined, modified, and refined to prevent conflict.

Even though it is possible to prevent the conflicts through better designs, to some extent conflicts may continue to occur during actual use. In this case, we believe the concept of "shared affordance" described by Leonardi [54] is relevant to conflict resolution during actual use. Leonardi suggests that the introduction of new technology only results in organizational change when "users converge on a shared appropriation of the new technology's features such that the affordances the technology provides are jointly realized." In order to achieve this shared affordance, it is important for employers to align their appropriation 
with their employees, and openly share and communicate their approach. For instance, with DOH devices employees are highly concerned about their privacy. If employers openly discuss how they are going to use the data for the benefit of employees - and not against them - and regularly communicate the outcome of their appropriation, they may positively influence their employees' attitudes towards the system.

\subsection{Limitations and future work}

While our study lays a foundation for identifying the impact of introducing consumerized IT into organizations based on their social structure, this work does have several limitations. The major restriction pertains to the sample and project setting of Active@work. Focusing only on two work environments, one with a high level of mental workload and the other with a high level of physical workload, served to limit our target sample to white and blue collar workers. In addition, despite the natural limitations of qualitative research, since this study was restricted to the pre-implementation phase, it was not possible to study actual appropriation. It is important to further investigate the impact of the identified tensions on user beliefs and actions during actual use, as it appears to be necessary to propose effective design guidelines for $\mathrm{DOH}$ technologies.

\section{Acknowledgement}

This research has been supported by the European Commission and the Swiss State Secretariat for Education, Research and Innovation (SERI) under the Ambient Assisted Living (AAL) Joint Programme.

\section{References}

[1] J. R. Wilson and S. Sharples, Evaluation of Human Work, 4 ed.: CRC Press, 2015.

[2] R. Fingas. (2015). IBM adopts Apple Watch for internal fitness initiative \& Watson-linked health app [u]. Available: http://appleinsider.com/articles/15/10/27/ibm-adopts-applewatch-for-internal-fitness-initiative-watson-linked-healthapp

[3] P. Olson. (2014). Wearable tech is plugging into health insurance. Available: http://www.forbes.com/sites/parmyolson/2014/06/19/wearable-tech-health-insurance/

[4] H. J. Wilson, "Wearables in the Workplace," Harvard Business Review, vol. 91, pp. 23-25, 2013.

[5] H. Banaee, M. U. Ahmed, and A. Loutfi, "Data mining for wearable sensors in health monitoring systems: a review of recent trends and challenges," Sensors, vol. 13, pp. 1747217500, 2013.

[6] A. Pantelopoulos and N. G. Bourbakis, "A survey on wearable sensor-based systems for health monitoring and prognosis," Systems, Man, and Cybernetics, Part C: Applications and Reviews, IEEE Transactions on, vol. 40, pp. 112,2010

[7] A. Mathur, M. Van den Broeck, G. Vanderhulst, A. Mashhadi, and F. Kawsar, "Quantified Workplace: Opportunities and Challenges," in The 13th International Conference on Mobile Systems, Applications, and Services, Florence, Italy, 2015.

[8] G. Pozzi, F. Pigni, and C. Vitari, "Explaining Big Data impact on healthcare organizations: a technology affordance approach," in ItAIS 2013 Conference Proceedings, 2014.

[9] P. M. Leonardi, "When flexible routines meet flexible technologies: affordance, constraint, and the imbrication of human and material agencies," MIS Quarterly, vol. 35, pp. 147-168, 2011.

[10] K. Ara, T. Akitomi, N. Sato, S. Tsuji, M. Hayakawa, Y. Wakisaka, et al., "Healthcare of an organization: Using wearable sensors and feedback system for energizing workers," in Proceedings of the 16th Asia and South Pacific Design Automation Conference, 2011, pp. 567-572.

[11] D. O. Olguín, B. N. Waber, T. Kim, A. Mohan, K. Ara, and A. Pentland, "Sensible organizations: Technology and methodology for automatically measuring organizational behavior," Systems, Man, and Cybernetics, Part B: Cybernetics, IEEE Transactions on, vol. 39, pp. 43-55, 2009. [12] A. Majchrzak and M. L. Markus, "Technology Affordances and Constraints in Management Information Systems (MIS)," in Encyclopedia of Management Theory, E. Kessler, Ed., ed: Sage Publications, 2012.

[13] B. Mittelstadt, B. Fairweather, M. Shaw, and N. McBride, "The Ethical Implications of Personal Health Monitoring," International Journal of Technoethics, vol. 5, pp. 37-60, 2014.

[14] G. Tartarisco, G. Baldus, D. Corda, R. Raso, A. Arnao, M. Ferro, et al., "Personal Health System architecture for stress monitoring and support to clinical decisions," Computer Communications, vol. 35, pp. 1296-1305, 2012.

[15] S. Patel, H. Park, P. Bonato, L. Chan, and M. Rodgers, "A review of wearable sensors and systems with application in rehabilitation," Journal of neuroengineering and rehabilitation, vol. 9, p. 1, 2012.

[16] S. Sneha and U. Varshney, "Enabling ubiquitous patient monitoring: Model, decision protocols, opportunities and challenges," Decision Support Systems, vol. 46, pp. 606619, 2009.

[17] L. Atallah, B. Lo, R. Ali, R. King, and G.-Z. Yang, "Real-time activity classification using ambient and wearable sensors," Information Technology in Biomedicine, IEEE Transactions on, vol. 13, pp. 1031-1039, 2009.

[18] M. L. Markus and M. S. Silver, "A Foundation for the Study of IT Effects: A New Look at DeSanctis and Poole's Concepts of Structural Features and Spirit," Journal of the Association for Information Systems, vol. 9, pp. 609632, 2008.

[19] P. M. Leonardi and S. R. Barley, "What's under construction here? Social action, materiality, and power in constructivist studies of technology and organizing," The Academy of Management Annals, vol. 4, pp. 1-51, 2010.

[20] P. M. Leonardi, "Ambient Awareness and Knowledge Acquisition: Using Social Media to Learn "Who 
Knows What" and "Who Knows Whom"," MIS Quarterly, vol. 39, pp. 747-762, 2015.

[21] R. F. Zammuto, T. L. Griffith, A. Majchrzak, D. J. Dougherty, and S. Faraj, "Information Technology and the Changing Fabric of Organization," Organization Science, vol. 18, pp. 749-762, 2007.

[22] Gibson and James J, Eds., The Theory of Affordances, The Ecological Approach to Visual Perception. Houghton Mifflin Harcourt, 1979, p.^pp. Pages.

[23] O. Volkoff and D. Strong, "Critical Realism and Affordances: Theorizing IT-Associated Organizational Change Processes," MIS Quarterly, vol. 37, pp. 819-834, 2013.

[24] G. Piccoli and F. Pigni, "Harvesting External Data: The Potential of Digital Data Streams," MIS Quarterly Executive, vol. 12, pp. 53-64, 2013.

[25] C. Vitari and F. Pigni, "DDGS Affordances for Value Creation," in Smart Organizations and Smart Artifacts, L. Caporarello, B. Di Martino, and M. Martinez, Eds., ed: Springer International Publishing, 2014, pp. 9-16.

[26] G. Pozzi, F. Pigni, and C. Vitari, "Affordance Theory in the IS Discipline: a Review and Synthesis of the Literature," in Twentieth Americas Conference on Information Systems, Savannah, 2014.

[27] A.-L. Fayarda and J. Weeks, "Affordances for practice," Information and Organization, vol. 24, pp. 236-249, 2014.

[28] S. Al-Natour and I. Benbasat, "The Adoption and Use of IT Artifacts: A New Interaction-Centric Model for the Study of User-Artifact Relationships," Journal of the Association for Information Systems, vol. 10, pp. 661-685, 2009.

[29] Active@work. (2016). Active Older Adults @ Workplace. Available: http://www.activeatwork.eu/

[30] K. M. Eisenhardt, "Building Theories from Case Study Research," The Academy of Management Review, vol. 14, pp. 532-550, 1989.

[31] T. J. Bouchard, "Field research methods: interviewing, questionnaires, participant observation, unobtrusive measures," in Handbook of Industrial and Organizational Psychology, M. D. Dunnette, Ed., ed Chicago, IL: RandMcNally College Publishing Company, 1976, pp. 363-414.

[32] A. L. Strauss and J. Corbin, Basics of Qualitative Research: Techniques and Procedures for Developing Grounded Theory, 2 ed. Newbury Park: Sage, 1998.

[33] D. J. Levinson, "Role, personality, and social structure in the organizational setting," The Journal of Abnormal and Social Psychology, vol. 58, p. 170, 1959.

[34] W. J. Goode, "A theory of role strain," American Sociological Review, pp. 483-496, 1960.

[35] J. R. Rizzo, R. J. House, and S. I. Lirtzman, "Role conflict and ambiguity in complex organizations," Administrative Science Quarterly, pp. 150-163, 1970.

[36] R. P. Bostrom, "Role conflict and ambiguity: Critical variables in the MIS user-designer relationship," in Proceedings of the seventeenth annual computer personnel research conference, 1980, pp. 88-115.

[37] J. Stewart, "Value conflict and policy change," Review of Policy Research, vol. 23, pp. 183-195, 2006.

[38] S. Newell and M. Marabelli, "Strategic opportunities (and challenges) of algorithmic decision-making: A call for action on the long-term societal effects of 'datification',"
Journal Of Strategic Information Systems, vol. 24, pp. 3-14, 2015.

[39] K. Askola, A. Toshimori, and M.-L. Huotari, "Cultural differences in the health information environments and practices between Finnish and Japanese university students," Information Research, vol. 15, p. 1, 2010.

[40] L. Baxter, N. Egbert, and E. Ho, "Everyday health communication experiences of college students," Journal of American College Health, vol. 56, pp. 427-436, 2008.

[41] Y. Zhang, "College students' uses and perceptions of social networking sites for health and wellness information," Information Research: An International Electronic Journal, vol. 17, p. n3, 2012.

[42] G. Mark, D. Gudith, and U. Klocke, "The cost of interrupted work: more speed and stress," in CHI 2008, 2008, pp. 107-110.

[43] F. R. H. Zijlstra, R. A. Roe, A. B. Leonora, and I. Krediet, "Temporal factors in mental work: Effects of interrupted activities," Journal of Occupational and Organizational Psychology, vol. 72, pp. 163-185, 1999.

[44] J. Harris, B. Ives, and I. Junglas, "IT consumerization: when gadgets turn into enterprise IT tools. MIS Quarterly Executive," MIS Quarterly Executive, vol. 11, pp. 99$112,2012$.

[45] S. Dewan and J. Ramaprasad, "Social Media, Traditional Media, and Music Sales," MIS Quarterly, vol. 38, pp. 101-121, 2014.

[46] J. Luo, S. Ba, and H. Zhang, "The Effectiveness of Online Shopping Characteristics and Well-Designes Websites on Satisfaction," MIS Quarterly, vol. 36, pp. 11311144, 2012.

[47] R. Garg and R. Telang, "Inferring App Demand From Publicly Available Data," MIS Quarterly, vol. 37, pp. 1253-1264, 2013.

[48] G. Zodik, "Future technologies supporting the convergence of Mobile, Wearables, and IoT," in Mobile Software Engineering and Systems (MOBILESoft), 2015 2nd ACM International Conference on, 2015, pp. 129-130.

[49] S. Köffer, E. Fielt, and B. Niehaves, "IT consumerization and its effects on IT business value, IT capabilities, and the IT function," in Pacific Asia Conference on Information Systems, Marina Bay Sands Expo and Convention Center, Singapore, 2015.

[50] A. D. Thierer, "The Internet of Things and Wearable Technology: Addressing Privacy and Security Concerns without Derailing Innovation," Richmond Journal of Law and Technology, vol. 21, pp. 6-15, 2015.

[51] T. A. Beehr, L. B. Johnson, and R. Nieva, "Occupational stress: Coping of police and their spouses," Journal Of Organizational Behavior, vol. 16, pp. 3-25, 1995.

[52] C. D. Fisher and R. Gitelson, "A meta-analysis of the correlates of role conflict and ambiguity," Journal of Applied Psychology, vol. 68, p. 320, 1983.

[53] S. E. Jackson and R. S. Schuler, "A meta-analysis and conceptual critique of research on role ambiguity and role conflict in work settings," Organizational Behavior and Human Decision Processes, vol. 36, pp. 16-78, 1985.

[54] P. M. Leonardi, "When does technology use enable network change in organizations? A comparative study of feature use and shared affordances," MIS Quarterly, vol. 37, pp. 749-775, 2013 